\title{
Decentralization of Social Services-Necessity, Responsibility, Development
}

\author{
Ma. Denada Seferi (Dibra) \\ Department of Social Policies and Sciences, Faculty of Social Sciences, University of Tirana, \\ Department of Social Service Policies, Ministry of Labour, Social Affairs and Equal Opportunities \\ Tirana, Albania \\ Mob:00355692088554, Mail:de.dibra@yahoo.it

\section{Ma. Etleva Zeqo (Murati)} \\ PhD in Process, Department of Social Service Policies \\ Ministry of Labour, Social Affairs and Equal Opportunities \\ Tirana, Albania \\ Mob:00355682081058, Mail:etlevaz@yahoo.com
}

\author{
Doi:10.5901/ajis.2013.v2n9p451
}

\section{Abstract}

This article will present the hypotheses on the decentralization of social interventions in Albania, it will contain proposals and recommendations regarding the most efficient way to use the current financial mechanisms but also innovative proposals regarding the implementation of new methods of integrated social service delivery possibilities.Decentralization of social interventions in Albania is a condition that can fully develop democratic process in the country. The idea of decentralization of social interventions aimed at promotion of a complex cooperation between different levels of government - State, Regions, Municipalities / Communes - to continuously operate to promote wider participation of citizens and social organizations in national and local government elections.Description of the current situation of decentralization, problems, achievements and providing social services in Albania, will be analyzed in this article.Innovative ideas on decentralization to disclose responsibilities, built on rules that make transparent decisions will guarantee the proper use of resources and a careful verification of the efficiency and effectiveness of interventions. Only a democratic process of this magnitude enables intelligent activation and available resources to support the difficult process to build an integrated system of social services. It is required to overcome the perception that social interventions are considered only as an expense but should be considered as an investment in human resources. Decentralization of social interventions - is in fact an "added value" that enables intelligent inclusive and sustainable economic growth'.

Keywords: decentralization, social intervention, integrated system of social services, financial mechanisms

\section{Introduction}

Profound transformation of the socio-economic policy in our country, in the 90th, made it necessary to undertake social policy, along with economic ones. Social programs were part of the social protection policies, in addition to social care, system of legal protection of workers, collective contracts, etc.. The mechanism that was used to change or operating of this policy was inter alia the creation of legislation, ministries, administrative structures and the creation of an efficient system of social care that will not only face the urgent problems of the period, but would resist the time and fit with contemporary standards.

Social policies were oriented towards the creation of a social protection system to achieve a specific legislation, law no. 7710 dated 18.5.1993, "On Social Assistance and Care2" during 1990-2000.

The social protection system includes three main programs managed and funded by the central government, such as the support to poor families, the support of persons with disabilities and the provision of social care services, primarily to residential one, for persons in difficulty and without support. In the above period (1992-1996) was established the

\footnotetext{
1 The three adjectives: smart, inclusive and sustainable are taken by the European Strategy 2020.

${ }^{2}$ Article 31 of the Law No. 7710 dated 18.5.1993, "On Social Assistance and Care"
} 
policy structure of the Ministry and administrative structures at central and regional level. The first two programs were half decentralized, while the program of social care services was centralized.

The legal framework completed, starts with the Constitution of the Republic of Albania ${ }^{3}$ which stipulates that local government is established based on the principle of decentralization of power and exercised according to the principle of local autonomy. (art.13).

After nearly half a century of centralized governance, Albania entered the path of political decentralization in 1992, the first democratic election were conducted in this period. Despite the importance of the political movement towards increased democratic representation, local administrative and fiscal autonomy remained very weak. However, the process of democratization of local government received a boost and began to change with the entry into force of the European Charter of Local Self-Government (ECLSG) on August 1st $2000^{4}$ as an important and mandatory part of the Albanian legislation.

Another important step is the Decentralization Strategy ${ }^{5}$ which is in line with ECLSG and and the Albanian Constitution. This strategy was drafted by the National Decentralization Committee and the Expert Group. For the first time, a long process of consultation, took place across the country between various representatives (local government, non-governmental organizations, local community, local businesses, and other stakeholders) that discussed on the strategy, policies and principles within it, trying to achieve even understanding. The international community also gave its full support 6 .

This strategic document was drafted at a significant time to those moments after the local government situation was quite delicate and with many problems: there were no clear definitions of responsibilities and functions but instead, they were very general and it was difficult to remove a dividing line between the responsibilities of local and central government, had significant overlap of functions/responsibilities in many areas, also the inconsistency of responsibilities with the authority to act, especially as a result of lack of financial resources? ${ }^{7}$.

This reform ${ }^{8}$ includes the contribution and the experience of all stakeholders in this process: Government, local government, civil society, donors and the international community.

Respect of the principle of decentralization is the best choice for the provision of social services and the most suitable for the beneficiaries of services. The implementation of this principle requires a new distribution of tasks and responsibilities between central and local government.

The main objectives of decentralization of social services aimed at: (i) poverty reduction through increased effectiveness of social assistance funds, (ii) quantitative and qualitative fulfillment of the needs of persons with disabilities, children, the elderly, disabled workers and other groups in need, through diversification and geographical expansion of community social services, (iii) decentralization and transfer of powers to local governments for cash payments and the provision of social services, (iv) de-institutionalization of social services; v) the involvement of civil society and public and private operators in the provision of social services in the community.

Under the 2005 legislation, the responsibilities of the structures are, Ministry of Labor, Social Affairs and Equal Opportunities MoLSAEO: (i) develop policies, designs strategies, national legislation, authorizes service providers, prepares standards and criteria of social services, while local government units, (ii) receive new powers for the administration of residential social care institutions, establishment and administration of services and their financing.

For the implementation of the decentralization process, interventions ${ }^{9}$ are undertaken in two directions;

\section{The transfer of residential service centers under the local government units.}

This initiative preceded by the entry into force of Law no 8743 , dated 22.02 .2001 "On the estate property of the state", as

\footnotetext{
${ }^{3}$ Article 13 of the Law no. 8417, dated 12.21.1998, "On the Constitution of the Republic of Albania".

4European Charter of Local Self-Government was signed by the Republic of Albania on 27/05/1998, ratified on 4/04/2000 and entered into force on 1/08/2000, Law No. 8548, dated 11/11/1999 "On the ratification of the European Charter of Local Self-Government".

5 "The national strategy of decentralization and local autonomy", DCM No. 615, dated 2/11/2000

${ }^{6}$ Stability Pact Conference, Fiscal Decentralization in SEE Countries, Case of Albania, 30 September 2006.

7 Strategjia kombëtare e decentralizimit dhe e autonomisë lokale", VKM Nr. 615, datë 2/11/2000.

8 The decentralization process is based on law no. 8652, dated 3107.2000 "On the organization and functioning of local government" and the Law no. 9355dated 10.03.2005 "On social assistance and services", as amended, which precedes the division of powers between central and local government.

${ }^{9}$ Social Protection Strategy 2007-2013, approved by DCM no.80 dated 28.01.2002, as amended
} 
amended, which regulates the rights of the State. The Law 8744, dated 22.02.2001 "On the transfer of estate public property to Local Government Units" as amended, provides too:

- estate properties to be transferred to the ownership or use of local government;

- regime of property rights, and

- administrative process of identifying property, listing, research and transfer and timetable for the various stages of this process too.

Transfer of residential social service institutions in the administration of local units create the opportunity for starting the process of a transfer of competencies and services at the local level along with property transfers from the central to local government administration, delegation of funds from MoLSAEO from the beginning of the year for each local unit, transfer of staff under the municipality administration. The transfer of services and competencies, carries with it the obligations arising from the law no. 8744 dated 22.2.2001 for the institution maintaining destination, ownership of facilities and services, destination of funds under the approved staffing etc.

In these conditions:

Local government units ${ }^{10}$, take all the competences for the management and delivery of services, beneficiaries acceptance in the institutions according to the needs and capacity of the institution, recruitment and appointment of staff etc.;

State Social Service SSS as executive institution retains responsibility MoLSAEO only institutions that remain in his administration that provide services nationally;

SSS, programs the needs for funding the normal functioning of institutions transferred to local governments; Inspect the implementation of quality standards and services Audits use of delegated funds from the central budget.

Also, this initiative was supported by fiscal decentralization system which can be defined as the most successful in the area of decentralization. The main objective of fiscal decentralization is to increase efficiency in the delivery of public services including social care. This objective can only be achieved if local governments were guaranteed secure income and a real degree of autonomy so that expenditure priorities can be planned and strictly enforced. ${ }^{11}$.

For the first time, the concept of unconditional transfers to local governments was used in the Law on State Budget 2001. Local government has full discretion in the use of funds for common functions and its functions. In the Law on State Budget the concept of unconditional transfers were distributed on the basis of a specific formula.

\section{Deinstitutionalization of residential social services}

Deinstitutionalization as a process of transition from residential services to the services closer to the biological family, family home model, began to apply for services to children.

Although these services are with a lower cost, compared with the typology of residential services, they guarantee the highest quality of services, convenience, respect of the rights of the individual and better family conditions for children welfare. Consolidation of services established and further development of this model remains a challenge for the future.

In general, in the area of benefit: local governments will provide services on the benefit of the local jurisdiction ${ }^{12}$, while the central government will provide services that include a national benefit field (as: monetary policy, national defense, planning and aggregate development, foreign affairs and trade, justice and security).

In Albania many of the national public services (as: compulsory military service, issuance of passports, some police services, consumer protection services, tax administration, treasury system services, statistical services, data collection and their distribution) are provided on decentralized basis ${ }^{13}$ nga agjencitë e pushtetit qëndror të ndodhura në territor, from central government agencies situated in the territory, while others may be attributed to local governments as delegated competencies and functions ${ }^{14}$.

Without underestimating the potential of new policies undertaken so far in Albania in the field of social interventions, which show the ability to operate in a decentralized way, it seems necessary to create a map of the

\footnotetext{
${ }^{10}$ Law no. 8653, dated 31.07.2000 "On the administrative-territorial units of local government of the Republic of Albania", as amended, Local Governance in Albania is organized in two levels of government.

11 World Bank Analytical Report "Albania, Decentralization in Transition", August 2004

12 The principle of subsidiarity

${ }^{13}$ Deconcentration means the horizontal transfer of power

${ }^{14}$ World Bank Analytical Report "Albania, Decentralization in Transition", August 2004
} 
outstanding problems in the system of social interventions in Albania. Identifying these problems is actually the starting point for identifying the structure of decentralization that we want to achieve.

The system of social interventions in Albania is concentrated in a centralized system. Planning of measures and disbursement of funds by MoLSAEO, is implemented through the state institution SSS which is an executive institution for the implementation of legislation ${ }^{15}$ and social policies of economic assistance scheme.

Albanian territory is divided into areas with high population density (such as the Municipality of Tirana), and in the center of the region with an average population and a large number of small local government structures that are present in rural and in mountainous areas.

Recently is thrown the idea to reduce the number of existent regions. It is responsibility of the Prefect the coordination and cooperation between central and local government. The Prefect ${ }^{16}$ is the only institution that verifies the validity of administrative acts of the institutions of local government at region / municipal level.

Regions and their councils are 2nd level bodies, formed by representatives of local government. Local government may delegate their functions, but till now there are no such experiences in the field of social interventions.

Regions work in the field of social intervention through "Committee for Assessment and Planning of needs ${ }^{17 "}$ and "the Section of assistance and social services."

Perform the function of coordination, data collection and planning of social interventions. Currently, professional human resources available to the department of social services assistance are very "few".

Local governments operate in the field of social interventions, primarily with the delivery of economic assistance. Restricted funds for economic assistance, payments for people with disabilities and social care, are funds by the MoLSAEO therefore included in the budget of the Ministry.

These funds are delegated to local governments that assess needs and make payments of economic assistance, persons with disabilities.Economic assistance funds are cash conditional funds to families in need, as well as and conditional funding for the community work and services. Only a small number of local governments manage social services mainly from the projects from "international donors".

Given this situation, despite the aforementioned decentralization process, are identified several "key problems" that seems mandatory and necessary to intervene:

1. The Centralized system currently in Albania, which is not pursuing an effective cooperation between different levels of government, provides social interventions aimed primarily at "the ratification of the damage" not that of promoting active inclusion.

2. The system of governance at national, regional and local level includes "donors" and European partners and international organizations but not Albanian social, cultural, economic and business organizations.

3. There is not a certain program to promote active participation of Albanian citizens.

4. Financial resources allocated for social intervention by the Albanian State are scarce and unreliable because it relates to a funding mechanism that determines the annual budget available. Professional resources available for system interventions are scarce and mainly attributable to the centralized system.

The Republic of Albania is pursuing the creation of a "Community Welfare" which provides a gradual approach to access to social services for all Albanian citizens. Priority interventions are for the benefit of persons and vulnerable groups.

This objective is already present in the Albanian legislation - paragraph 2 of Article 1 of Law 9355/2005 - which requires "reducing poverty and exclusion for individuals and families, as well as create opportunities for their integration through the provision of a system of interventions and services to improve their way of life."

Reorganization, expansion, training of an integrated and decentralized network of social services, health, educational, cultural, vocational training, employment, housing, are presumed valid condition for inclusive and sustainable development of the country.

Decentralization of social interventions is assumed as a valid condition for fully rooted democratic process, through the promotion and affirmation of citizen participation and Albanian social actors in national and local government decisions.

\footnotetext{
${ }^{15}$ DCM no. 542 dated 27. 07.2005 "On the approval of state social service status".

${ }^{16}$ Law No. 8652, dated 31.07.2000, "On the organization and functioning of local government"

${ }^{17}$ DCM. 563 , dated 12.08 .2005 "On the determination of the district responsibilities related to the delivery of social care services"
} 
Decentralization allows local communities to take many decisions rather than central authorities, in order to promote good governance, economic development, eficiency of delivering public services and to satisfy the interests of different communities.

In finalizing the separation of functions, actors must maintain a clear distinction between the types of modalities of decentralization.

Local governments will have responsabilities to citizens. Usually government services are designed by following the method "inside-out", they reflect the structures and procedures, designed mainly from the perspective of the internal service provider rather than as a complement to the needs of citizens. Establishment and implementation of the standards of services used as an instrument to satisfy the demands of citizens with the services provided by the institutions of central and local government. Standards of services are usually based on the needs and expectations/what citizens expect arre considered as defining principles of services. Increasing citizen's satisfaction is one of the key parameters to measure the success.

To pursue these goals, the decentralization of social services should fully activate consultation between the State, Region and Local Government in accordance with the principles of subsidiarity, cooperation, effectiveness, efficiency, cost-effectiveness, uniformity, funding etc..

To the Albanian public institutions belong the role of "Leading" the system of social interventions, planning and organization of social interventions, monitoring and verification of the results obtained, to ensure that within their competences the Albanian public institutions promote at all levels the role of social, cultural, and economic actors and donors, in order to harmonize their concrete and effective consultation in design and implementation of an integrated system of interventions, to predict that Albanian public institutions at all levels should promote the active participation of citizens in terms of identification of needs, priorities to chose, the operation of services and assessment of their results, to ensure that public institutions at all levels prepare actions for the creation and support of social enterprises; to ensure that public institutions at all levels will prepare actions to increase the contribution of volunteers in the provision of social services.

In this context, we propose that local government should carry out the following activities: on the planning, design, implementation of local systems of 'social service', the indication of priorities and innovation sectors. These tasks should be carried out in consultation with the social actors of the territory with the activation of permanent instruments of the comparison. Municipalities exercising such activities should prepare "three-year programs of social interventions", with its appropriate funding. Program schedule must be submitted for opinion to NGOs, donors and international collaborators operating in their territory, in order to activate and develop all possible synergies for the implementation of this program.

The relevant funding programs must be approved by the Municipal Council and the results should be reported and compared year after year, pilot projects provide for the active participation of citizens in the reading needs, to select priorities, service operation and evaluation of results to their promotion of volunteerism and reading needs and preparing management services to support actions to create social enterprises and training, authorization, licensing and supervision of all social structures and services within their territory, based on criteria and guidelines established by the national authority. If they are not able to perform this task they should delegate this function to the Region to participate in the procedure for identifying different areas of network services that will be determined at the regional level, to coordinate the programs and activities of institutions operating public services within the network (eg health, education, vocational training, etc.) in order to achieve an operational connection through services, to provide services and make active the economic assistance scheme through activation of funds through work in the community. To provide economic assistance it is obligatory the opinion expressed by the Regional Council; fees apply provided for users who benefit from the services, on the basis of criteria established at the regional level.

Regions, exercise the functions of planning, coordination and management of social interventions also monitoring their implementation at the local level, regulation and integration of social network interventions. These tasks are performed through consultation with the stakeholders of the social territory with the introduction of benchmarking tools. Regions exercise the functions assigned to them by "three-year social intervention programs" set in collaboration with local government, prepared with its own funds.

Programming scheme is presented for an opinion from NGOs, international donors operating in the territory, in order to activate and develop all possible synergies for the implementation of this program. Programs are subject to approval by the Regional Council and the results should be reported and compared year after year.

Meanwhile, the role of the Regions should realize the determination of integrated policies in the network and in agreement with the local government for the territorial delineation of social interventions, in order not to be inconsistencies and overlap; definition, based on the minimum requirements set by the State of the criteria for accreditation, authorization and supervision of structures and services and eventual exercise of those functions delegated 
by the local government; establishing criteria for setting tariffs for people who benefit from these services; assessment based on the requirements set out by the state, of the local government proposals Municipality about providing economic assistance; preparation of programs and provision of appropriate funds for the training and retraining of personnel involved in social activities; preparation of programs and provision of appropriate funds for the development of volunteering and to support the creation and qualification of social enterprises.

While State powers belong to the direction, coordination and control of social policy, namely: the definition of social policy objectives through the three-year program of social intervention. The content of the program will be sent for opinion of the social actors and national representatives, NGOs, donors and international collaborators, in order to activate and develop all possible synergies for the implementation of this program. The content of the program will be sent for opinion to the Parliament and the results should be reported and compared year after year, determining of the essential and uniform level to ensure, through intermediate stages social assistance and benefits for the Albanian citizens, the minimum structural and organizational conditions for the authorization in services and social structures, the definition of conditions and professional profiles in the field of social professions; definition of a minimum number of indicators of social data collection, in which should participate the Regions in agreement with local government; distribution of National Fund for Social Policy.

As a conclusion of the above analysis can affirm that the current performance of the process of decentralization of social services, in addition to the above positive achievements that each central, regional and local level have their clear duties, role and functions (based on the full legal framework), there have been negative fluctuation or variations aspects that can be reviewed, such as the administration of social services provided in residential social care institutions that have passed in the ownership of large municipalities.

But these reforms show that the decentralization process is dynamic and is in its consolidation phase. Some of the issues requiring solutions: the unclear role of the Region as a unit of the second level of local government, the lack eficiency in delivering services, missing of the inter-local planning, lack eficiency in providing coordination in different forms and levels of planning, full transfers of financial competencies and resources for capital investment. These issues are closely linked to the principle of subsidiarity and regional development approach to domestic needs.

First instruments on the reorganization and decentralization of social interventions, are "three-year programs of social intervention", prepared at the national, regional and local level (in single / joint / or decentralized form). Such programs should absolutely contain proposals for financing them so they do not become "a program with good intentions, but short-lived".

Promotion of social enterprises and cooperatives will be a new alternative way to social services.

The above proposed interventions shows an approach to the countries in the European Union with regard to the evolution of the process of decentralization that should also oriented towards a universal service approach (European Commission 2006/2007). To meet this challenge, were identified measures such as quality assurance and involvement of beneficiaries (users), services provided by the private sector along with the development of public-private partnerships to supplement public funds. These new approaches result in the recognition of the role of "social economy" that includes the supply as non-profit social cooperatives and other types of social enterprises.

It is necessary to undertake a comprehensive assessment of the nature and objectives of regional social services. This assessment should: give current services that are close to people, meet vital human needs, particularly the needs of vulnerable social groups. In the best case social services (European Commission 2007) should provide protection from the hazards of life, assist in personal challenges or crises, they are provided to families in different social situations, for their support in caring for children, elderly, and people with disabilities, they should guarantee basic human rights and contribute to non-discrimination, gender equality, health protection.

Another proposal regarding clarification of shared competence has to do with central government funding. In some cases it is not specifically defined the power of each authority, it brings, that some of these powers (social services) remain unfunded by the central government and as a result unrealised. Services should be characterized as an asymmetric relationship between providers and beneficiaries, this is a different relation from that between merchant and commercial suppliers. Services often include the local and cultural tradition to suit the needs of the beneficiaries.

Service providers have the need for a greater autonomy to address the wide varieties of social needs, given that social services are driven by the principle of solidarity and depend heavily on public funding to ensure equality of access of wealth or income.

Developing of personal budgets, or preparation of different packages based on the costs for beneficiaries, will enable the selection of the quality of social care services. This iniciative will make this area more competitive and will encourage the maintaining of the quality of care. 
Increasing and (the lack) of local government management capacity is often used as a pretext to delay the exercise of (transfering of) responsibilities. Currently, the staff of local government bodies is trained and this excuse can not be used any more. More than lack of capacity, there is often weakness in job place financing.

Creating of a nationwide management system of social services will enable better identification and assessment of needs, to promote awareness of the rights and facilitate the development of specialized direct services. It will also expand the access to services, especially for vulnerable and marginalized groups. Non-profit organizations, community groups, social business will be partners in this process. Creating a nationwide management network of social services, summarizes the procedures and methodology that will be used at central and local level, for providing multifunctional integrated social services for vulnerable groups at the national level.

To meet this challenge, have been introduced measures such as establishment, quality assurance, and the involvement of the beneficiaries, decentralization of services at local or regional level, external services of private sector and the development of public and private partnerships to meet public funding.

These proposals should be reflected in the new Strategy on Social Protection and Social Inclusion 2013-2020, as the entire completion of the decentralization process associated with the financial mechanisms.

All these approaches in Albania have found their place in the new strategies that the government is drafting in favor of decentralized social service delivery.

\section{References}

Law no. 8417, dated 21/12/1998, "Constitution of the Republic of Albania"

European Union Strategy $2020 \mathrm{http}: / /$ ec.europa.eu/eu2020/pdf/

Karta e Autonomisë Lokale: http://www.coe.int/ onventions.coe.int/Treaty/Social European Charter (revised).

Law No.8744, dated 22.2.2001 "On the transfer of the immovable property to the state's public LGUs".

Law no. 9355 dated 10.03.2005 "On the social assistance and services" as amended

Law no.9936, dated 26.06.2008 "On the system of budget management in the Republic of Albania".

Law no. 8653, dated.31.07.2000 " On the administrative-territorial units of local government of the Republic", as amended

DCM No. 542 dated 27. 07.2005 "On the approval of the State Social Service Status", as amended

UN Convention on the Rights of People with Disabilities - approved on UNO Assembly on 9 Dec 1975

The right of social security, Proff. Igor Tomes, 1997,

Process and the institutions of Social Policy, Merita Xhumari, 2010

Analyses focused on citizens' opinions -Rapport April 2010-Quality of Social Services: UNDP \&UEJL

Local development policies and instruments - Oriona Muçollari

Albania: Decentralisation in tranzition - World Bank Report 2004 